\title{
D03
}

\section{Leakage Through Top Seals During Reservoir Production}

\author{
L. Grande* (Norwegian Geotechnical Institute) \& F. Cuisiat (Norwegian \\ Geotechnical Institute)
}

\section{SUMMARY}

Some drainage of pore fluids in the top seals might occur at the time scale of production due to changes of pore pressure in the reservoir. The resulting compaction may have consequences for the sealing capacities of the cap rock, as it could induce leakage along the well annulus. In order to investigate capillary effects and drainage of intra-reservoir and/or overburden seals, special laboratory tests have been performed in NGI's rock mechanics laboratory. Examples of the depth of influence of the reservoir pressure diffusion (depletion) inside a top seal are given on a field scale. Also the additional compaction due to drainage from the cap rock, under burden and mudstone intervals within the reservoir is investigated on a field scale with a $1 \mathrm{D}$ coupled consolidation program. The additional compaction and settlement are found to be significant and this may affect the wells or installations in an unfavorable way (well failure or leakage along wells etc). It is therefore important to characterize not only the hydro-mechanical behavior of the reservoir sediments during production, but also that of the near non-pay sediments. 
Owing to their low permeability, it is traditionally assumed that the cap rock, under burden and non - reservoir sediments are not drained and compacted during depletion. However, closer examinations of some shallower reservoirs have shown that some drainage of pore fluids in the seals might occur at the time scale of production due to changes of pore pressure in the reservoir, which would give more compaction and subsidence than if only considering compaction from the sand rich production intervals. A larger settlement in overburden might result in failure of wellbore casing. Such settlement may also have some consequences for the sealing capacities of the cap rock, as it could induce leakage along the well annulus due to failure in the cement or at the casing-cement interface (Figure 1). These mechanisms cannot be foreseen if the drainage potential of the seals is not assessed.

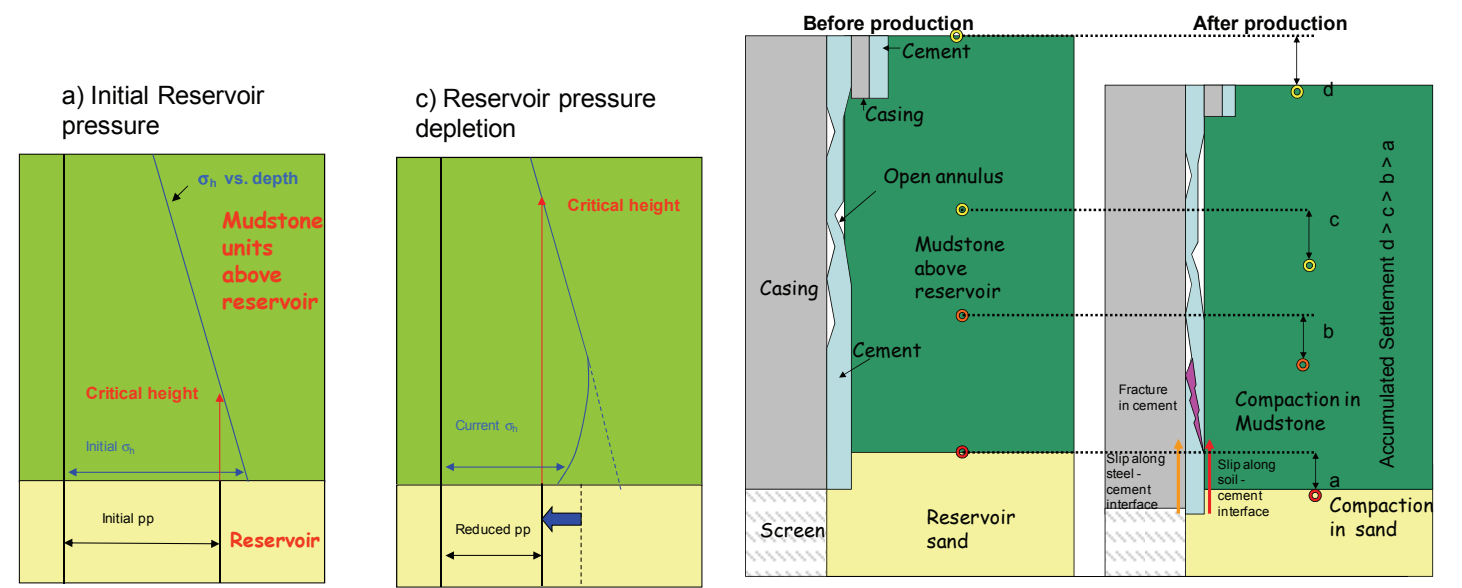

Figure 1 Production related changes in the fracture gradient (left) and possible unfavorable production related mechanisms with respect to leakage along a well trajectory (right).

In order to investigate capillary effects and drainage of intra-reservoir and/or overburden seals (mudstone), special laboratory tests have been performed in NGI's rock mechanics laboratory. The reservoir consists of a shallow buried reservoir system of sand rich intervals (sandy debris and tidalites) in a complex interbedding with more silty smectite rich mudstones (muddy debris flows and tidalites). The overburden mudstones are also rich in smectite.

In the experiment, a brine saturated mudstone sample from the overburden is first consolidated applying stress and pore pressures corresponding to in-situ stress. The sample is then subjected to a slight gas overpressure at the one end simulating gas saturated sandstone in contact with brine saturated mudstone. The gas pressure is then reduced at one end while the brine pressure is maintained in the other end to investigate critical pressure / flow for fluid displacements. The deformations in the mudstone specimen triggered by the applied pressure gradient are measured.

During the one-dimensional consolidation, the deformation of the clay is controlled by the coefficient of consolidation $\mathrm{c}_{\mathrm{v}}$ given by:

$c_{v}=\frac{k \cdot M}{\mu}$

where $k$ is the permeability $\left(\mathrm{m}^{2}\right), \mathrm{M}$ the constrained modulus (Pa) and $\mu$ the fluid viscosity (Pa.s).

Values of $\mathrm{c}_{\mathrm{v}}$ for overburden shales are scarce. Measurements on some deep shales performed at NGI are taken as a lower value ( $\mathrm{c}_{\mathrm{v}}$ around 1-1.5 $\mathrm{m}^{2} /$ year). However the data are not representative for this specific field study area. An estimation of $c_{v}$ for the non-reservoir sediments and cap rock of the study area based on published permeability data for pure 


\section{E Fault and Top Seals Montpellier 2009}

smectite gives much higher values, around $50 \mathrm{~m}^{2} /$ year. Note that the uncertainty is high because of lack of good permeability data.

The depth of influence $\mathrm{H}$ of the reservoir pressure diffusion (depletion) inside the clay can be estimated from the coefficient of consolidation:

$H=\left(\frac{c_{v} \cdot t}{T}\right)^{0.5}$

where $\mathrm{T}$ is a dimensionless time equal to 0.05 at full pressure influence.

For a depletion time $\mathrm{t}$ of 8 years, Eq. (2) gives a depth of influence $\mathrm{H}$ equal to circa $15 \mathrm{~m}$ for $\mathrm{c}_{\mathrm{v}}=1.5 \mathrm{~m}^{2} /$ year, and $\mathrm{H}$ equal to almost $90 \mathrm{~m}$ for $\mathrm{c}_{\mathrm{v}}=50 \mathrm{~m}^{2} /$ year. Hence on a production time scale, the zone of influence of the pressure changes in the reservoir is not negligible.

The additional compaction due to drainage from the clay intervals is investigated with a 1D coupled consolidation program. The analyses show that the increase in settlement due to consolidation of the overburden and underburden is up to $4.1 \mathrm{~m}$ when using the upper range of expected permeability value. This should be compared to an estimated reservoir compaction from pressure reduction in the production pay zones of $3.75 \mathrm{~m}$ in this specific study. Further compaction may occur due to consolidation of the intra-reservoir clay layers. The analysis shows a total increase of compaction up to $12.7 \mathrm{~m}$ using a high estimate of the permeability. Hence drainage of clay may contribute to a large part of the total reservoir compaction and total settlement, depending on the clay permeability. This additional compaction and settlement may affect the wells or installations in an unfavorable way (well failure or leakage along wells etc).

An increase in the overall effective stresses by reservoir depletion may give a more favorable situation in terms of an increased margin with respect to the fracture gradient, see Figure 1 (left). However, relative displacements induced by the depletion may lead to failure in annular cement, slip along soil-cement interface or slip along steel cement interface with the consequence of gas flow from the open annulus (Figure 1, right). It is therefore important to characterize not only the hydro-mechanical behavior of the reservoir sediments during production, but also that of the near non-pay sediments. 